\title{
EDITORIAL
}

\section{Remember the people dimension of scientific management}

Operatlonal research, with Its emphasls on scientiflc enqulry, measurement and emplrlcal analysis, has its orlglns in what F.W.Taylor called "scientlflc management". As enunclated by Taylor, the principles of sclentlfic management Include:

(1) development of a "science" to replace rule-of-thumb working knowledge;

(2) scientific selection and development of individuals;

(3) combining the results of work study with selected and trained employees;

(4) intlmate, friendly co-operatlon between management and the workforce.

The first princlple Involves an attempt to determine the best way of performing work by systematlc analysls of that work. A starting polnt for thls is careful study of the method of working adopted by the highest-performing Individuals. The second principle involves selecting individuals on the basis of their abilities and potential for development, followed by training in the most interesting and profitable class of work available for which their abilities are suited. Co-operation of employees in implementlng scientific management is assumed to be achievable through higher rewards and improved working conditions in return for higher productivlty. One of the most famous applications of Taylor's principles was to the shovelling of iron ore and rlce coal at the Bethlehem Steel Company. After the costs of developing a new system for the shovelling operations, a $50 \%$ reduction in costs was achieved, and the average wage of men on the labour gang increased by $60 \%$ (Taylor, 1947).

The success of scientiflc management has led to its development into a number of increasingly specialized management support functions which include work study, organization and methods, operational research, and staff selection, appraisal and development. This is not surprislng: sclentific management itself implles progressive division of work to high levels of specialization in the pursuit of efficiency and increased productivity. Increasing sophistlcatlon of technlques can also encourage specialization and narrowing of focus. For operational researchers who see a wider role for their work, such pressures can be troublesome, as indicated in the article by Willam Keddie and Stephen Buttrick in this issue, entitled "Moving out of the backroom".
The emphasls of OR has always been on the first princlple of scientific management - the development of a science to replace rule-of-thumb working knowledge rather than on the "people-orlentated" principles 2-4. A related difference from other scientific management approaches is OR's emphasis on a system or unit within an organization, rather than on the performance of individuals. The typlcal and usually distlnctive approach has been to develop a quantitative model of the system of interest, in order to gain an understandlng of the system's operation and thereby to recommend to management ways of improving the system's performance. Not surprisingly, this has led to a focus on logistical operatlons such as production scheduling, distrlbution, capacity planning, inventory control, resource utilizatlon, reliability and maintenance, project planning, etc. In all of these areas, the behaviour of indlviduals In the system tends to be treated in a programmable fashlon, constructed models assume that, In aggregate, the people In the system will behave In predictable ways. To the extent that this is a reasonable assumptlon, OR based on quantltative models can be extremely effective in improving the performance of systems.

\section{Figure 1: Factors influencing performance}

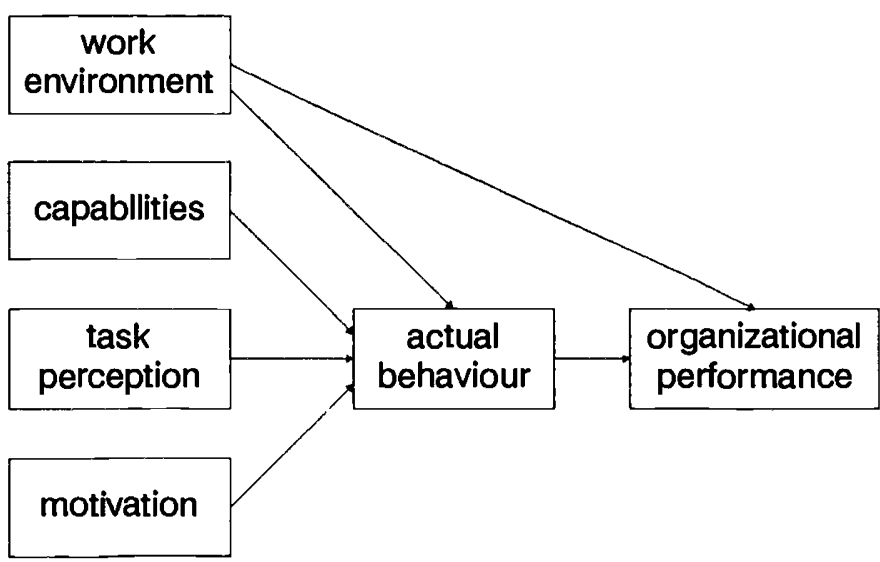

As illustrated in Figure 1, a people perspective on organizational performance suggests at least four main influencers of indlvidual behaviour: the work environment; the capability of Individuals; job perception; and motivation. It follows that improvements in performance may be achieved by addressing one or more of these four areas. From a people perspective, scientific management, as defined by the principles 
above, is effective in improving the individual's contribution to organizational performance because it addresses each of these four areas. The first principle of scientific management is concerned with the study of the work environment, which includes the tools, techniques and machinery needed for high performance. The second principle recognizes the importance of tralning and ability in increasing performance and making the most of individual capabilities. With scientlfic management, capability is improved by continuous monitoring and training of low-performing workers. The setting of work goals inherent in scientific management clarifies an individual's task perception and helps to ensure appropriate behaviour. Motivation is enhanced because the performance required to obtain given rewards is specified and there is a clear indication that a given level of effort will achieve the required performance.

In the context of Figure 1, OR interventions seek improvements in organizational performance primarily by providing managers with improved tools and technlques, i.e. by enhancing the work environment. Often interventions are also aimed at clarifying objectives and hence a manager's task perception. Frequently, improved task perception and improved capabillty through insights from a model are welcome side-benefits of an intervention. However, motivation, if it is considered at all, tends to be a concern of operational researchers only at the implementation stage, when there is concern about overcoming resistance to change. This is a pity, because many management problems may be more effectively handled by improving motivation than by seeking improvements in efficiency or control.

Why should this lack of people emphasis in OR matter? If quantitative approaches offer a means of improving organizational performance, then OR of the kind outlined has a significant contribution to make. However, for an increasing number of practitioners, this is not enough. Many wish to maximize their impact on organizational performance. Some would prefer to be addressing strategic concerns of their organization, rather than pursuing, as they see it, fine-tuning of ongoing logistical operations. This is not so much a denigration of interventions which are concerned with improving the efficiency of existing operations, but more a recognition that limited OR expertise ought to be applied where it can do most good.

Of course, OR is not confined to problems which can only be expressed in quantitative terms. The so-called "soft" approaches, such as strategic options development and analysis, soft systems methodolgy and the strategic choice approach, are evldence that operational researchers can also use their problemstructuring expertise to address qualitative strategic problems.

One qualitative, and increasingly strategic, issue of concern to organizations is the motivation of their employees, often expressed as a need for a strong corporate culture. There is a growing recognition, encouraged by best-selling books like In Search of Excellence, that employees themselves may offer the greatest potential for improving organizational performance. If this Is really the case, then OR as currently perceived by many practitioners, academics and managers does not have the expertise to help realize this potential. OR is not really a people-orientated scientific management approach. If $O R$ is to be seen as a truly versatile, strategic and continuing major contributor to corporate performance, then this gap in expertise needs attention. Perhaps organizations need to make a more concerted effort to build multi-disciplinary teams which can provide a more complete and integrated approach to scientific management.

\section{STEPHEN WARD}

\section{For the interested reader}

Peters, T. J. and Waterman, R. H., Jr (1982): In Search of Excellence, Harper \& Row, New York, USA.

Taylor, F. W. (1947): Scientific Management, Harper \& Row, New York, USA. 